\title{
Funding in English Universities and its relationship to the Research Excellence Framework
}

\author{
Anthony Kelly^ \\ University of Southampton, UK
}

The purpose of the Research Excellence Framework (REF) is to judge the quality of research in the $\mathrm{UK}$ and on that basis to apportion to universities, in a transparent manner, differential shares in the UK’s $£ 1.6$ billion pot of research funding. However, the funding process is anything but transparent! While the REF process was known years in advance and remained constant throughout the assessment exercise, the mechanisms for the subsequent award of quality-related research (QR) funding in England were opaque and 'adjustable'. The financial outcomes were put in the public domain following publication of the REF outcomes, but the calculations still remain a 'black box' even for experienced university administrators. The funding factors were not revealed in advance and dramatic changes were made to the formula once the REF results were known. This paper explores the intricacies involved in university QR funding and looks at the correlations between it and various REF outcomes. It discusses the tactical implications for academics and university administrators, and whether simpler alternatives that are just as effective can be developed in time for the next iteration.

Keywords: university funding; higher education funding; research assessment; REF

\section{Introduction to the Research Excellence Framework}

The Research Excellence Framework (REF) exercise, previously called the Research Assessment Exercise (RAE), is a fearsome assessment undertaken on behalf of the UK government to gauge the quality of research in UK universities. It is unique to the UK though paler imitations have been introduced in places such as Hong Kong (Hong Kong University Grants Committee, 2014). ${ }^{1}$ It is a high-stakes competition used informally by the media to rank universities and their departments in league tables, but more importantly is used formally to allocate to universities their individual shares of the $£ 1.6$ billion pot of UK quality-related (QR) research funding and reshape the research landscape with larger units. The command and control effect of the REF on funding can be dramatic; for example, the effect of the University of Manchester slipping from 8th in 2008 to 17th in 2014 meant a loss of £69 million (more than 17\%) in its 2015 QR income (Jump, 2015b). This would have been much worse had the weightings for $4 *$ and $3 *$ research stayed at the original 3:1 ratio, but HEFCE changed the ratio to $4: 1$ on 20 February $2015,{ }^{2}$ a manœuvre that suited larger universities with high proportions of $4 *$ outcomes (Frankel \& Ransow, 2015).

ॠSchool of Education, University of Southampton, Highfield, Southampton SO17 1BJ, UK. Email: a.kelly@soton.ac.uk 
Research assessment exercises were undertaken in 1986, 1989, 1992, 1996, 2001, 2008 and 2014. Submissions from each academic discipline are ranked by peerreview panels against agreed quality standards and within a framework that recognises variation between academic subjects, but the exercises have always been controversial and some university vice-chancellors have suggested that they are too time-consuming and too expensive (Rothwell, 2008; Floud, 2015; Whiteley, 2015) ${ }^{3}$ and the cost of staging the exercises is increasing. The $2008 \mathrm{RAE}$ cost $£ 47$ million whereas the cost of the 2014 REF was more than $£ 120$ million, excluding the cost of panellists' time (Chambers, 2015). ${ }^{4}$ The cost of the impact portion of the 2014 exercise alone is estimated at $£ 55$ million, which equates to approximately $£ 7500$ and 30 days work per impact case study (Jump, 2015c).

The validity of attempting to gauge the value of scholarship in this fashion, even when employing an expert review process, has also been widely debated [e.g. Stronach (2007) vs Brown (2007)], but universities and their constituent departments have taken the exercises very seriously and aggressive decisions are made as to which staff are submitted and which are excluded (see Lucas, 2015). For the 2014 REF, employment contracts were commonly redrafted to reflect strategic decisions, with those staff not submitted typically being put on teaching-only contracts [Times Higher Education (THE), 2015] and their careers 'potentially wrecked by the decision to exclude' according to Sir Roderick Floud (2015), former President of Universities UK. The report on the $2008 \mathrm{RAE}$ said that universities were more selective in 2008 than they had been in previous iterations (RAE, 2009, p. 1) and this trend continued into REF 2014. For example, in Education, there were 103 submitting departments and 2806 staff in 1996; 83 departments and 2055 staff in 2001; 82 departments and 1903 staff in 2008; and 76 departments and 1446 staff in 2014 (cited in Lucas, 2015). ${ }^{5}$

\section{The REF 2014 methodology}

In total, there were 36 academic subjects or 'units of assessment' (UoA) covering the full range of academic departments in the UK's 154 universities. ${ }^{6}$ UoAs were assessed by subject-specific panels of 'experts' using a common framework, with formative and ongoing moderation within and between panels.

For each UoA, $65 \%$ of the overall grade was awarded for staff publications or 'outputs', $20 \%$ to the demonstrable 'impact' of the research and $15 \%$ to the research 'environment' of the submitting department. ${ }^{7}$ These three grades were then weighted and brought together for each submitting department to produce an overall 'grade profile' using five different quality categories: $4 *$ for world-leading; $3 *$ for internationally excellent; $2 *$ for internationally recognised; $1 *$ for nationally recognised; and 'unclassified' (U) for research falling below the standard of nationally recognised work. ${ }^{8}$ The data published by the Higher Education Funding Council for England (HEFCE) in December 2014 at the end of the REF assessment process - the 'REF results' - did not aggregate these grade profiles into a combined overall grade point average (GPA), but this was done for each university or department by newspapers like the Times Higher Education (THE) and their methodology is described in the next section. 
Essentially, 'outputs' comprised the collected 'best-four' publications from each returned member of staff for the six years from the start of 2008 to the end of 2013, with reductions allowed for early career researchers, part-timers and those who had periods of leave and/or disabilities. 'Impact' was assessed using impact case studies (ICS) that described the non-academic impact of the department's research during the REF period. One ICS plus one additional ICS for each 10 staff submitted (rounded to the nearest 10) was required; so, for example, a department submitting 27 full-time equivalent (FTE) staff was required to submit four ICS. Finally, 'environment' was assessed on the basis of various aspects of the submitting department such as the number of doctoral completions, the amount of research income won during the REF period and the department's research and staffing strategies.

Only academics who had a contract of employment of at least 0.2 FTE on the census date (31 October 2013) and whose primary employment function was to undertake research (with or without teaching) were eligible for submission to the REF. Research assistants, unless they were named as principal investigators on prestigious research grants, were not eligible because they were deemed not to be 'independent researchers in their own right' (HEFCE, 2011) and there were additional rules to accommodate National Health Service personnel and similarly attached (so-called 'category C') staff.

\section{League table methodology}

The newspapers weighted the grade profiles as follows: they multiplied the percentage of $4 *$ research by 4 ; the percentage of $3 *$ research by 3 ; the percentage of $2 *$ research by 2 ; and the percentage of $1^{*}$ research by 1 . The totals were then summed and divided by 100 to produce a GPA between 0 and 4 for each university and for each university department. ${ }^{9}$

'GPA tables' were published by the THE on 18 December 2014 following the publication of the REF results by HEFCE the same day (Jump, 2014). ${ }^{10}$ This was followed two weeks later by its 'research intensity tables' (Jump, 2015a). Research intensity (RI) is a new and positive addition to the existing suite of interpretive metrics because RI takes account of the proportion of eligible staff submitted. University departments have their overall GPA weighted according to the fraction of eligible staff they submitted. Research intensity is similar to research power, which is GPA multiplied by the raw number of staff submitted. Both are attempts to combine volume with quality in a way that produces a more accurate picture of achievement than that produced by quality alone.

\section{Exposing and exploring the HEFCE methodology for recurrent QR funding}

Recurrent ${ }^{11}$ QR funding from HEFCE comes in six parts: QR charity support funding; QR business research funding; QR research degree (RDP) supervision funding; $\mathrm{QR}$ funding for national research libraries; mainstream $\mathrm{QR}$ funding; and (where applicable) a London weighting on the mainstream $Q R$ element. The 'mainstream QR' element is by far the largest and is calculated solely on the basis of the REF results. To put the relative amounts in perspective, by way of a real-life example, 
Table 1 shows the actual distribution of QR funding for the University of Southampton issued by HEFCE in March 2015 following the 2014 REF.

The 'mainstream QR' element is calculated as follows. HEFCE converts the REF quality profile results to FTE, and the $4 *$ and $3 *$ components are weighted 4 and 1 respectively ${ }^{12}$ and summed. The result is then multiplied by HEFCE using an undeclared 'unit funding factor' for each UoA, which is UOA-specific and ranges from approximately $£ 10,500$ to approximately $£ 19,500$. Funding was distributed between the four main panels on the basis of cost-weighted volume, but somewhat mysteriously, HEFCE did not publish the unit funding factors; they have to be retro-calculated post facto from the final mainstream QR amounts awarded for each UoA under each of the three REF sub-categories of outputs, impact and environment. An analysis carried out for this paper of all the QR data for English universities suggests that UoA 36 (Communication, Cultural and Media Studies) has a relatively low unit funding factor of $£ 10,626$ and that each UoA in Panel B (Science and Engineering) has a relatively high factor of $£ 19,671$. For Education, in main panel C (Social Sciences), which has a weighting of ' 1 ' (i.e. is not a high-cost clinical or intermediatecost subject), the funding unit turns out to be $£ 11,026$ (c.f. the worked example below). The total mainstream $\mathrm{QR}$ income for an entire university (£32,481,640 for the University of Southampton example) is then the sum of all its constituent UoAs.

Adjustments that had been put in place to protect STEM areas following the 2008 RAE were discontinued under the 2015 formula because STEM activity had increased to pre-2008 levels, so 2014 saw a boost in funding for Arts, Humanities and Social Sciences, notwithstanding the fact that HEFCE provided a transitional allocation of $£ 28$ million for STEM subjects, outside the recurrent budget, to ease the pain.

Here is a real-life example for UoA25 (Education) again using actual figures from the University of Southampton (HEFCE, 2015a). The calculation starts with the actual REF results (see Table 2).

Table 3 shows the REF profile converted to FTE; for example, 17.9\% (for $4 *$ outputs) of 22 FTE staff submitted is equivalent to 3.938 .

Table 4 shows the FTE profile converted to quality weighted volume. $4 *$ research is given a weight of 4 and $3^{*}$ research is weighted 1; so, for example, $3.938 \mathrm{FTE}$ (for $4^{*}$ outputs) is equivalent to 15.752 . Funding only follows $4^{*}$ and $3 *$ research, so the $2^{*}$ and $1^{*}$ cells on Table 2 are ignored in the conversion to quality weighted volume on Table 4 .

Table 1. Example of QR funding for the University of Southampton

QR funding example: University of Southampton

Mainstream QR income

$£ 32,481,640$

London weighting on mainstream QR

$£ 0$

QR charity support fund

$£ 3,175,595$

QR business research element

$£ 1,786,971$

QR RDP supervision fund

$£ 7,955,037$

QR for National Research Libraries

$£ 0$

Total QR income

$£ 45,399,243$ 
Table 2. Example of REF results profile: UoA25, University of Southampton

\begin{tabular}{lllcll}
\hline & $4^{*}$ & $3^{*}$ & $2^{*}$ & $1^{*}$ & $\mathrm{U}$ \\
\hline Outputs & 17.9 & 51.3 & 29.5 & 1.3 & 0 \\
Impact & 76.7 & 23.3 & 0 & 0 & 0 \\
Environment & 25 & 62.5 & 12.5 & 0 & 0 \\
No. staff returned & 22 & & & & \\
\hline
\end{tabular}

Table 3. Example of REF results profile converted to FTE staff: UoA25, University of Southampton

\begin{tabular}{lcclll}
\hline & $4^{*}$ & $3^{*}$ & $2 *$ & $1^{*}$ & $\mathrm{U}$ \\
\hline Outputs & 3.938 & 11.286 & 6.49 & 0.286 & 0 \\
Impact & 16.874 & 5.126 & 0 & 0 & 0 \\
Environment & 5.5 & 13.75 & 2.75 & 0 & 0 \\
\hline
\end{tabular}

Table 4. Example of FTE results converted to quality weighted volume ( $£ \mathrm{QR} / \mathrm{QWV} F T E)$ : UoA25, University of Southampton

\begin{tabular}{llcllll}
\hline & \multicolumn{1}{c}{$4^{*}$} & $3^{*}$ & $2^{*}$ & $1^{*}$ & $\mathrm{U}$ & Total \\
\hline Outputs & 15.752 & 11.286 & 0 & 0 & 0 & 27.04 \\
Impact & 67.496 & 5.126 & 0 & 0 & 0 & 72.62 \\
Environment & 22 & 13.75 & 0 & 0 & 0 & 35.75 \\
\hline
\end{tabular}

Note: QWV=Quality Weighted Volume

Table 5 shows the actual mainstream QR funding awarded by HEFCE for UoA 25 in Southampton and from this (and similar calculations made for all the other UoA25 in England) it is possible to retro-calculate the unit funding factors for UoA25 for all universities, as follows. The total amounts awarded by HEFCE under each sub-profile, as in Table 5, are divided by their respective quality weighted volumes, as per Table 4 . This produces $£ 8013$ for outputs, $£ 1748$ for impact and $£ 1,265$ for environment, which sum to $£ 11,026$. An analysis carried out for this paper shows that this is the same for every UoA25 in every university in England. ${ }^{13}$ Interestingly, these amounts represent $73 \%, 16 \%$ and $11 \%$ respectively of the total $(£ 11,026)$, and not the expected $65 \%, 20 \%$ and $15 \%$ ratios that HEFCE had advised universities:

... the appropriate weighting of REF elements [of] 65 per cent for outputs, 20 per cent for impact and 15 per cent for environment, ... will be used in a way which ensures that the funding allocated follows [these] agreed percentage weightings. Funding for mainstream quality-related research $(\mathrm{QR})$ will therefore be disaggregated according to how the subprofiles in REF 2014 contribute to the overall quality profile (that is, 65 per cent for outputs, 20 per cent for impact and 15 per cent for environment), with calculations of funding undertaken separately for each sub-profile area. (HEFCE 2015b, online: Section 5, Subsection b) 
Table 5. Example of actual funding: UoA 25, University of Southampton

\begin{tabular}{lcccr}
\hline Sub-profile component & Outputs & Impact & Environment & Total \\
\hline Amounts & $£ 216,666$ & $£ 126,920$ & $£ 45,214$ & $£ 388,800$ \\
\hline
\end{tabular}

It can be seen now, on foot of the above analysis, that the 65:20:15 weightings were applied by HEFCE at sector level and not individually within each UoA or individually within each university, as was expected and reported. So rather than outputs, impact and environment all competing with different 'handicaps' for the same $£ 1048$ million pot, they are competing for three separate pots of $£ 680, £ 210$ and $£ 158$ million (which are the total amounts for mainstream QR funding for England for 2015/ 16).

Further analysis carried out for this paper shows that most UoAs across the four main panels are very similar to the 73:16:11 weightings applicable to UoA25. For example, the weightings are 73:13:10 for Clinical Medicine (UoA1), 71:17:12 for Philosophy (UoA32), 71:17:12 also for Modern Languages (UoA28) and 74:15:11 for General Engineering (UoA15).

It is worth noting that the 2008 and 2014 methodologies produced almost identical financial outcomes, though there was greater precision (two decimal places) in the 2014 iteration. It is also worth noting that since the actual number of staff returned was taken into account (along with GPA, of course), HEFCE based its REF 2014 funding on research power (the raw number of staff returned) rather than research intensity (the fraction staff returned as a percentage of the total staff eligible for return).

For completeness, other elements of the total QR funding ( $£ 45,399,243$ for the University of Southampton) are calculated as follows: ${ }^{14}$

- 'London weighting' (not applicable in the case of the University of Southampton) is calculated as a percentage of the mainstream element, so to that extent it is REFdependent. It is calculated as $12 \%$ for institutions in Inner London and $8 \%$ for institutions in Outer London. For example, the London weighting for Imperial College is $12 \%(£ 5,811,487)$ of its mainstream QR funding of $£ 48,429,085$; whereas that for St Mary's University (Twickenham) is $8 \%(£ 27,401)$ of its mainstream QR funding of $£ 342,534$.

- The purpose of 'national research libraries funding' is to support five research libraries designated by HEFCE, following a review in 2007, as being 'of national importance'. This was zero in the case of the University of Southampton.

- Neither the 'QR charity support' ( $£ 3,175,595)$ nor the 'QR business research' $(£ 1,786,971)$ elements are REF-dependent. QR charity support and QR business research funds are distributed in proportion to institutions' research income (in 2012/13 and 2013/14) from charities and from business respectively.

- The 'QR research degree programme (RDP) supervision' element $(£ 7,955,037$ in the case of the University of Southampton) is REF-dependent (for the first time in 2014). Taking as an example UoA 25 in the University of Southampton, it is 
calculated as follows. Table 6 shows the overall REF result calculated from Table 2 using the 65:20:15 weightings for outputs, impact and environment.

This produces a 'quality score' of 0.788 , which is the amount of $3 *$ and $4 *$ research as a proportion of the total research $\geq 2 *$ (see Table 7 ). The Education department in the University of Southampton had 29.28 FTE doctoral students two years previously (allowing for certain adjustments), which when multiplied by the quality score, gives a 'weighted FTE' of 23.07. The HEFCE funding multiplier was $£ 4630,{ }^{15}$ which produced funding of $£ 106,807$ for the year.

\section{Exploring the relationship between HEFCE funding and REF outcomes}

The datasets for HEFCE funding and for the REF outcomes for English higher education institutes (HEI) are shown together on Table 8. Only multi-disciplinary universities in receipt of both teaching and research funding are included ${ }^{16}$ and $\mathrm{QR}$ funding figures exclude transitional funding (see note 9 ).

An example will serve to illustrate the data in the table. The University of Oxford received a teaching grant of $£ 19,364,990$ and a QR grant of $£ 139,061,600,{ }^{17}$ so that QR made up $87.78 \%$ of its total $(£ 158,426,590)$. Oxford achieved an Overall GPA in the 2014 REF of 3.34 when all its individual departments/UoA were weighted for size and coalesced, having returned 2409 staff, which was $87 \%$ of the total number of staff eligible for submission. Oxford University therefore achieved a research power of $8047(3.34 \times 2409)$ and a research intensity $(\mathrm{RI})$ of $2.9(87 \%$ of 3.34$)$. It achieved a GPA for its impact of 3.51 so that impact power was $8457(3.51 \times 2409) .{ }^{18}$

The relationships between HEFCE funding and the various REF outcomes are shown in Table 9. The Pearson ${ }^{19}$ for the relationship between overall GPA and QR funding is a relatively low, although still significantly positive, 0.5810 , but this is not surprising given that HEFCE QR funding is based on the weighted proportion of $4 *$ and $3 *$ research across all three REF components and on the number of staff returned by the UoA; in other words, it is possible to have a high GPA but a low proportion of $4 *$ outputs and a low number of staff returned and this would (and from HEFCE's point of view, should) result in lower funding. What is perhaps surprising is that the

Table 6. Example of overall REF results: UoA25, University of Southampton

\begin{tabular}{llllll}
\hline & $4 *$ & $3 *$ & $2 *$ & $1 *$ & $\mathrm{U}$ \\
\hline Overall REF result & 31 & 47 & 21 & 1 & 0 \\
No. staff returned & 22 & & & & \\
\hline
\end{tabular}

Table 7. Example of QR RDP supervision funding: UoA25, University of Southampton

\begin{tabular}{cccc}
\hline Quality score & PGR FTEs & Weighted PGR FTEs & QR RDP supervision fund \\
\hline 0.788 & 29.28 & 23.07 & $£ 106,807$ \\
\hline
\end{tabular}

Note: PGR=Postgraduate research student 


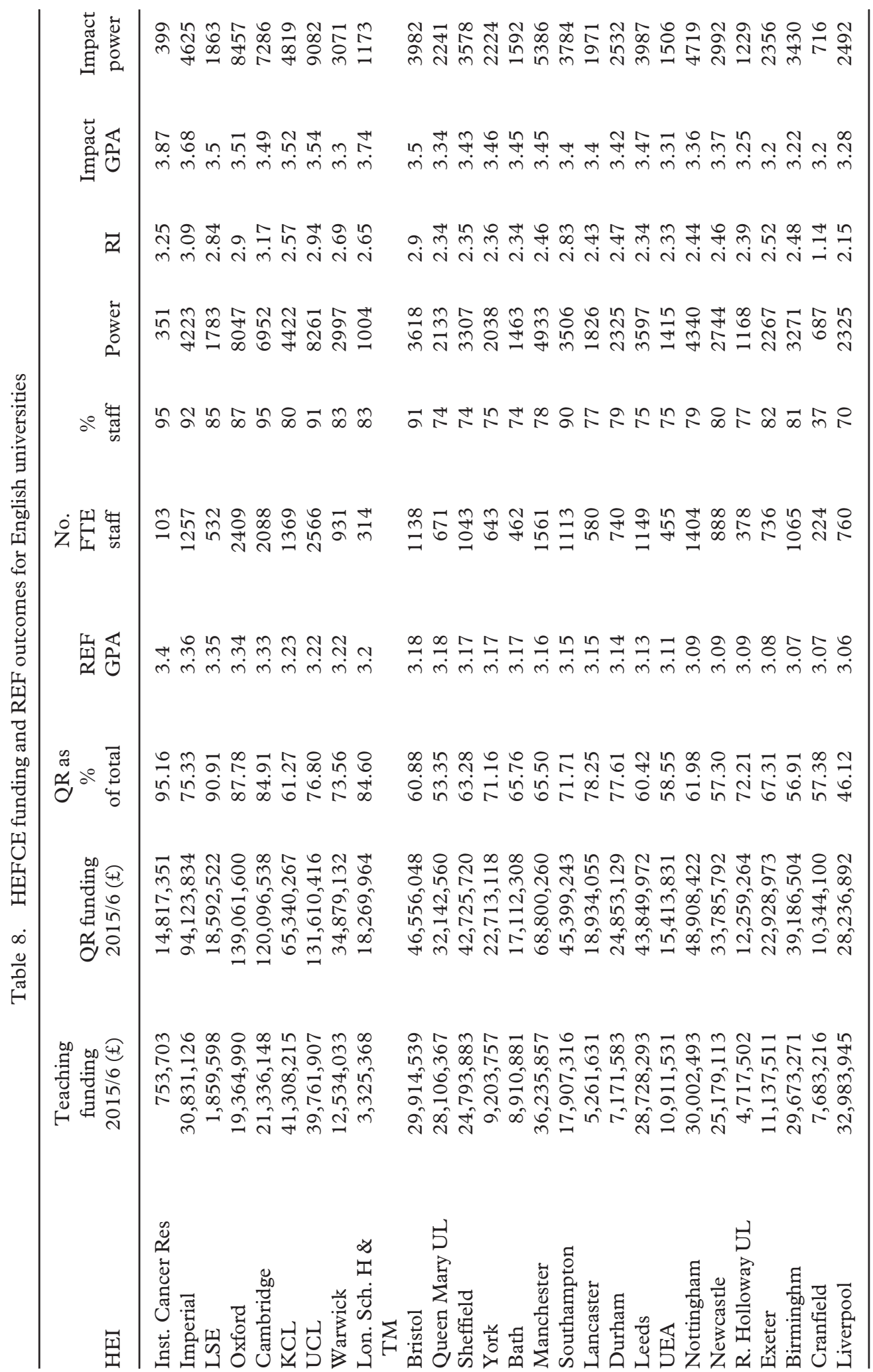




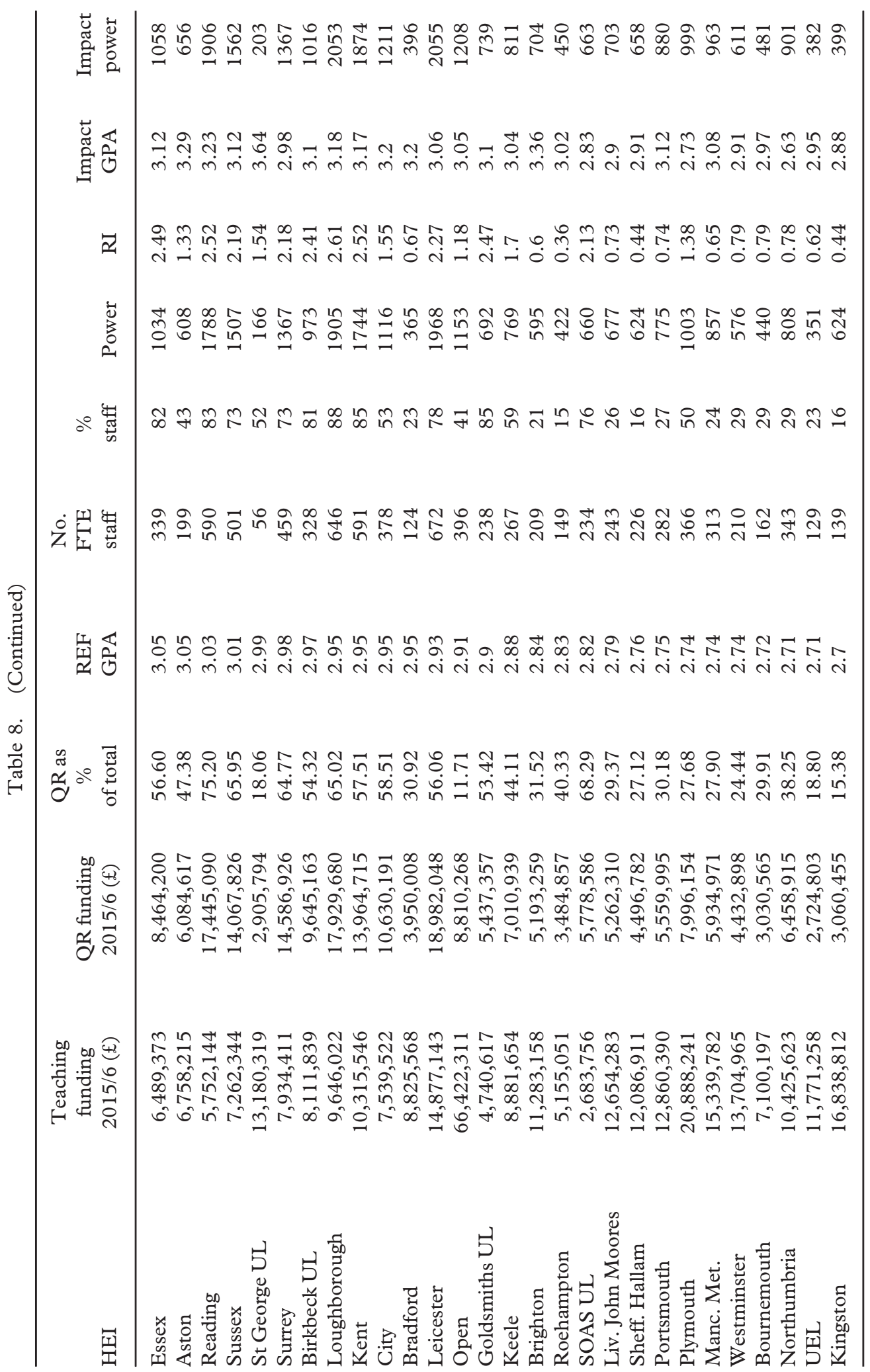




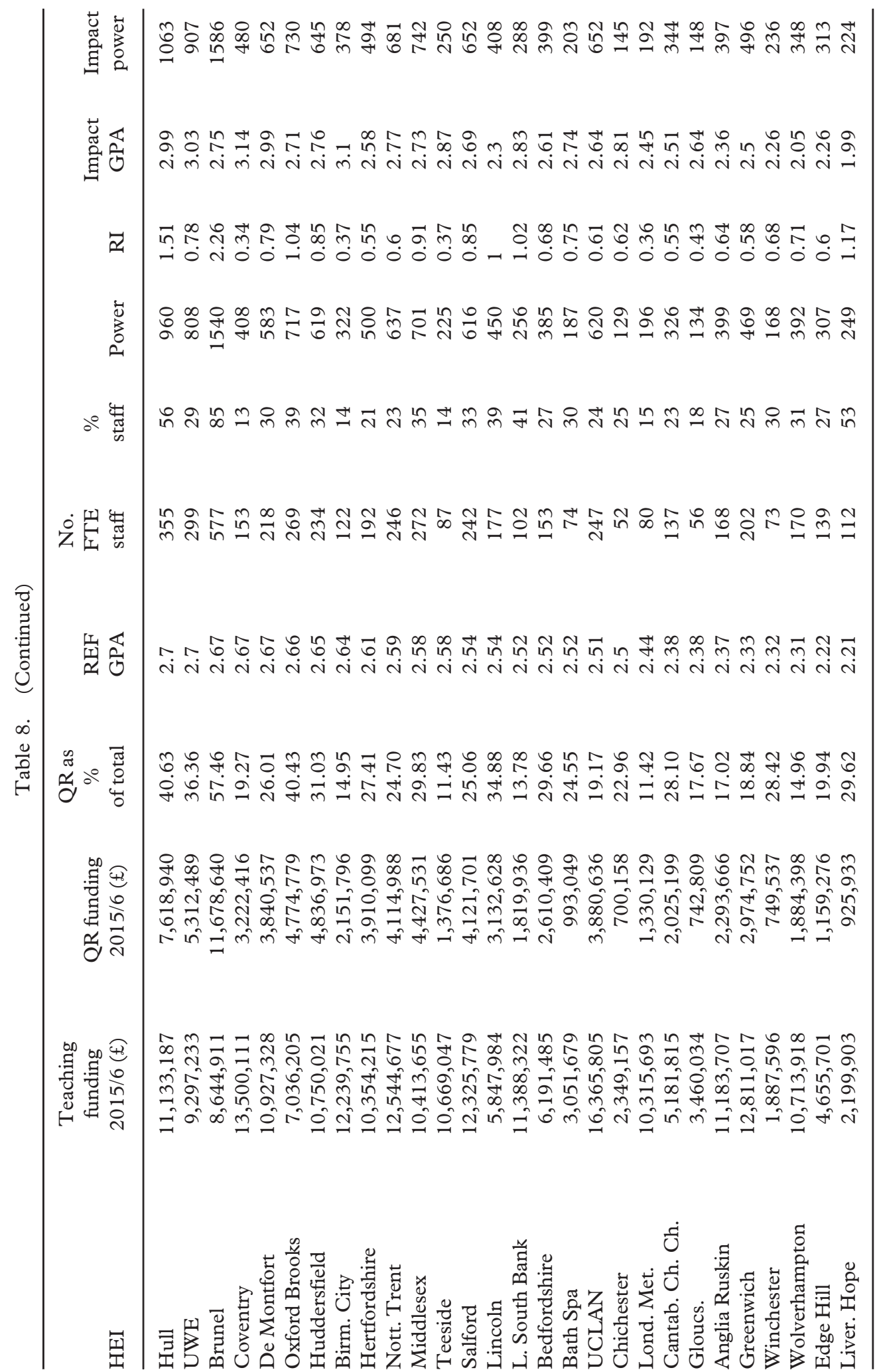




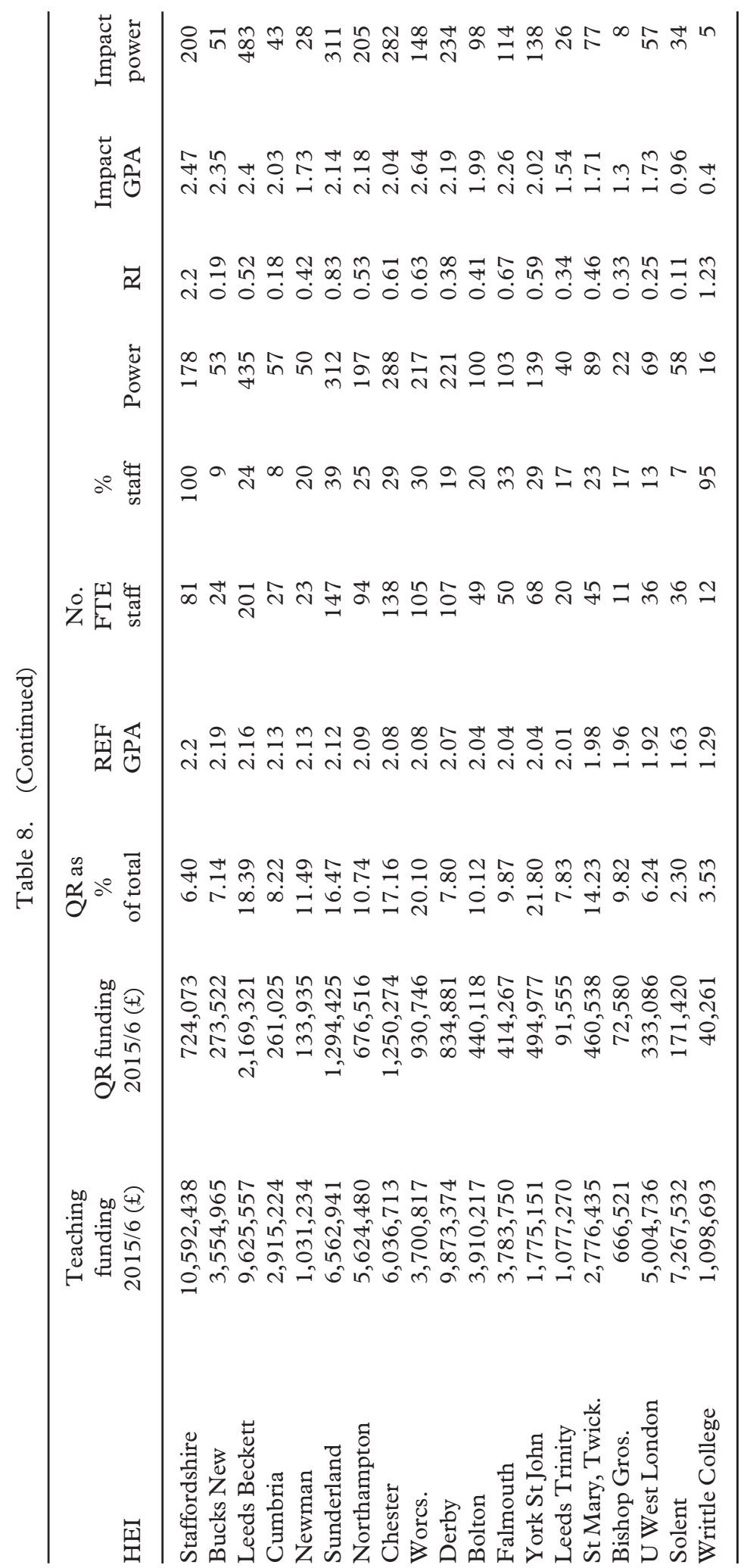


Table 9. Correlations between HEFCE funding (both teaching and QR) and REF outcomes

\begin{tabular}{lcc}
\hline Variables & Pearson & Spearman \\
\hline Teaching funding vs Overall GPA & 0.4631 & 0.4839 \\
Teaching funding vs number FTE & 0.6382 & 0.6379 \\
returned & & \\
Teaching funding vs Power & 0.6281 & 0.6324 \\
Teaching funding vs Research intensity & 0.3693 & 0.3215 \\
Teaching funding vs Impact GPA & 0.4418 & 0.5002 \\
Teaching funding vs Impact power & 0.6328 & 0.6237 \\
Teaching funding vs QR funding & 0.5804 & 0.5936 \\
QR funding vs Overall GPA & 0.5810 & 0.9421 \\
QR funding vs number FTE returned & 0.9667 & 0.9625 \\
QR funding vs Power & 0.9754 & 0.9761 \\
QR funding vs Research intensity & 0.6652 & 0.8494 \\
QR funding vs Impact GPA & 0.5006 & 0.8839 \\
QR funding vs Impact power & 0.9747 & 0.9810 \\
\hline
\end{tabular}

relationship between GPA and HEFCE teaching funding is almost as strong (Pearson 0.4631 ) as the relationship between GPA and QR funding, and that the relationship between the two HEFCE funding grants is as strong as it is (Pearson 0.5804), but this may be explained by the fact that the heavily weighted teaching grants for STEM subjects are primarily located in the higher performing research-intensive universities.

In three cases, the Spearman ${ }^{20}$ coefficients are much higher than the corresponding Pearson coefficients: (i) between QR funding and GPA where the Spearman is 0.9421 and the Pearson is 0.5810 ; (ii) between $\mathrm{QR}$ funding and research intensity where the Spearman is 0.8494 and the Pearson is 0.6652 ; and (iii) between QR funding and impact GPA where the Spearman is 0.8839 and the Pearson is 0.5006 . We can infer from this that the QR funding data is non-normal and non-linear. ${ }^{21}$ Since the Spearman is computed on ranks it depicts monotonic ${ }^{22}$ relationships while the Pearson is based on true values and depicts linear relationships, so if the Spearman is greater than the Pearson, as with the above correlations between QR Funding and $\mathrm{REF}$ outcomes, it indicates a monotonic and not a linear relationship.

The correlation between QR funding and research intensity (Pearson 0.6652; Spearman 0.8494) is higher than that between QR funding and GPA (Pearson 0.5810; Spearman 0.9421), and this is also to be expected. Research intensity is essentially GPA adjusted for the fraction of eligible staff returned so it takes (albeit limited) account of the number of staff returned, which is a factor in the funding formula. However, the strongest correlation is that between $\mathrm{QR}$ funding and research power (Pearson 0.9754; Spearman 0.9761) and again this is as it should be from HEFCE's point of view. Research power is GPA adjusted for the raw number of staff returned and this is theoretically closest to the funding formula, which rewards large research 'powerhouses'. Breaking research power down into its two constituent parts (GPA and raw number returned), we can see that the relationship is almost as strong (Pearson 0.9667; Spearman 0.9625) between QR funding and the number of FTE staff returned as it is between $\mathrm{QR}$ funding and research power, but that the 
correlation between QR funding and GPA is much weaker (Pearson 0.5810). So universities that want to maximise funding from the REF, as opposed to those who want to maximise league table position, need to concentrate on returning a large raw number of staff rather than returning a smaller number of staff in pursuit of a higher GPA.

Although impact power is very strongly correlated with QR funding (Pearson 0.9747; Spearman 0.9810), impact GPA is even less significant (Pearson 0.5006) for QR funding than overall GPA (Pearson 0.5810). This situation is the result of the multiplying effect of staff numbers and the fact that only $3^{*}$ and $4^{*}$ research is counted for funding purposes.

\section{Conclusions}

While peer review is widely regarded as 'the gold standard of research assessment' (Jump, 2015e), the use of bibliometrics such as the ' $h$-index' are being touted as alternatives for use in the next REF. The h-index is a measure of the volume and citation performance of papers, and some (e.g. Bishop, 2015) have argued that since it is a good historical indicator of how much $\mathrm{QR}$ funding departments receive from HEFCE, it could act as a proxy for the REF in this respect. However, although the hindex has been shown to 'work' for some UoAs (e.g. Psychology), it is known to 'fail utterly' (Jump, 2015e) for others (e.g. Physics). The publisher Elsevier, which owns the citation index Scopus, has also looked at using citations data as a replacement for the current mode of REF assessment. They analysed the proportion of outputs at university/institutional level that fell into the top $5 \%$ of citations and compared these figures with the proportion of $4 *$ outputs in the $2014 \mathrm{REF}$, finding a correlation of 0.59 but with plenty of outliers. At the departmental/UoA level, they created a 'bibliometric GPA' based on the proportion of articles whose citations fell within the top 5, 10, 25 and 50\% globally and compared this with output GPA from the REF, finding that correlations ranged from a high of 0.76 (for Biological Sciences) to a negative low of -0.04 (for Anthropology), ${ }^{23}$ and again there were serious outliers and counter-examples. The problem with these bibliometric alternatives to peer review seems to be related to the significance presence of outliers, which even high correlation coefficients can mask. As the Elsevier researchers guardedly concluded, while bibliometrics might be 'useful in informing REF evaluations in some UoAs', they can only 'predict results to some extent' (Jump, 2015e), so short of making more and better use of technology in future REF iterations, the search goes on for a simple but accurate replacement for the current approach. The reputational stakes of the REF quality assessment and the financial stakes of the REF-QR link are so huge that the current high-cost peer-review process cannot be easily discarded, especially for something that is known to be unreliable.

A 'work-around' might be to preserve the REF for quality assessment, but to decouple it from university funding. Whatever the arguments about the cost, both real and opportunity, of the REF as currently constituted and the spurious accuracy created by league tables compiled subsequently by third parties, the processes are at least transparent and constant, and the criteria well known and well understood in advance. The same cannot be said for the way the REF is linked to $Q R$ funding, which is obtuse and (it seems deliberately) opaque. The final HEFCE funding 
amounts are put into the public domain, but the funding criteria are not known in advance of the assessment exercise and the 'black box' calculations are not understood even by senior university administrators. For example, counter to what had been assumed by universities for years leading up to the $2014 \mathrm{REF}$, the 65:20:15 funding weightings for outputs, impact and environment were applied by HEFCE at sector level and not individually within each UoA or university, so it turned out that the three REF components had their own separate QR pots. HEFCE did not publish the unit funding factors, either before or after the exercise and changed the weightings for $4^{*}$ and $3^{*}$ research two months after the REF results were published (Else, 2015), all of which creates the impression that the funding formula is manipulated to arrive at a 'satisfactory' settlement for certain universities or groups of universities. This is not necessarily detrimental to the sector, but it discredits the REF as an assessment exercise and makes the use of it for funding purposes questionable.

In terms of that exact relationship between HEFCE funding and the REF results, some of the emerging correlations appear to satisfy HEFCE's remit and suggest what that 'work-around' might be. The correlation between QR funding and overall GPA is positive but relatively weak, which is just as HEFCE intended given that only $4 *$ and 3* research was rewarded. The correlation between $\mathrm{QR}$ funding and (i) power, (ii) impact power and (iii) the number of FTE staff returned, are all exceptionally high and again this is as HEFCE intended because it rewards large research-intensive universities in HEFCE's drive to make the UK world-leading in research terms. However, the correlation between QR funding and 'number of staff returned' is so strong and straightforward that the 'work-around' referred to above- that is to say, how to preserve the REF as an assessment exercise while decoupling it from use as the determinant of university funding - might simply be to base $Q R$ funding on the number of staff returned; perhaps grouped in funding and quality bands to reflect the stepped monotonic nature of the relationship. The necessary staff data is available to HEFCE from the Higher Education Statistics Agency (HESA), thus obviating the need for the REF as far as funding is concerned, and in that respect this work-around is much cheaper and almost as accurate as the alternative of basing funding on research power, which in theory is a slightly stronger relationship.

Although the 2008 and 2014 QR funding methodologies produced almost identical financial outcomes for universities, and notwithstanding any future work-around regarding the REF and its role (or non-role) in QR funding, there are also tactical and policy-making implications consequent on the above analysis. The tactical consequence for universities of the high correlation between $\mathrm{QR}$ funding and the number of FTE staff submitted (compared with that between QR funding and GPA, say) is that universities going for 'gold' before 'glory' will need to return a large raw number of staff and not just a large percentage of eligible staff, irrespective of whether or not the current $\mathrm{REF}-\mathrm{QR}$ link is maintained.

Consistent with looking for a 'cheaper-but-just-as-accurate' work-around, the final question is where this leaves 'impact'. Although impact power, like all 'powers', is very strongly correlated with $Q R$ funding because of the staffing element, impact GPA is even less significant for QR funding than overall GPA, and at a cost of $£ 7500$ per impact case study - a total of $£ 55$ million excluding staffing and opportunity costs (Jump, 2015c) - it seems a very expensive component of the REF exercise that does 
not per se add anything as far as funding is concerned. So if HEFCE increases the weighting from the current $20 \%$ for the next REF, there is an even stronger case for not using the REF for funding purposes.

\section{NOTES}

1 Hong Kong held research assessment exercises (RAE) in 1996, 1999, 2006 and 2014. The assessing panels consisted mainly of UK academics. For example, in 2014, of the 21 panel members for Education, nine were from the UK, four were from Hong Kong itself, three were from the USA, three from Australia, and one each from Singapore and Canada (Hong Kong University Grants Committee, 2014).

2 Following a HEFCE board meeting on 2 February (Else, 2015).

3 'The correlation between changes in funding between 2014 and 2015 and the grade point averages received by universities for their research staff is negative $(-0.32)$. In other words, institutions that did poorly in the REF ended up doing well in terms of increases in their budgets.' See Whiteley (2015).

4 The current REF framework 'steals years and possibly centuries of staff time that could be put to better use and includes so many outcome measures that every university can cherry-pick its way to appearing top-ranking.' See Chambers (2015).

5 The proportion of staff submitted for the RAE 2008 is impossible to calculate, but 'indicative figures' suggest that $59 \%$ of eligible staff were submitted in 2008 compared to $55 \%$ in 2014 (Jump, 2015d).

6 Twenty-six submissions were received from 'single-subject universities' like the Courtauld institute of Art and the Royal College of Music. The remaining 128 universities submitted to multiple UoAs. Occasionally, a university made more than one submission to a UoA and sometimes two or more universities made a joint submission.

7 For the 2008 RAE, $70 \%$ was allocated to outputs, $20 \%$ to environment and $10 \%$ to esteem, and the figures were then rounded to the nearest 5\%. So REF 2014 represents an attempt to arrive at a more fine-grained assessment than in previous iterations.

8 For impact: $4 *$ indicated 'outstanding'; $3 *$ 'very considerable'; 2 * 'considerable'; 1 * 'recognised but modest'; and U 'unclassified'.

9 To convert individual UoA grade profiles into a single institutional/university quality profile, the tables weighted the UoAs by the number of full-time equivalent staff submitted, so that larger departments counted for more in calculating a university's overall ranking. HEFCE itself did something similar for allocating its research funding in 2009 (HEFCE, 2009), but used a different, theoretically superior (Kelly, 2012) weighting system: 7,3 and 1 for $4 *, 3 *$ and $2 *$ activity respectively (with zero weighting for $1^{*}$ and ' $U$ '). As things turned out, following the $2014 \mathrm{REF}, \mathrm{HEFCE}$ weighted $4 *$ research four times more heavily than $3 *$ research (Jump, 2015b).

10 The data was released under embargo by HEFCE the previous day. The media also produced GPA tables for outputs only and for impact only, alongside their overall GPA tables.

11 As a one-off measure for 2015/16, HEFCE additionally provided two transitional allocations for research outside the main recurrent grant to mitigate the impact on institutions of changes to the amounts allocated for some STEM (Science, Technology, Engineering and Mathematics-including Medicine for research funding purposes, but not for teaching funding) subjects arising from the transition from RAE 2008 to REF 2014 (HEFCE, 2015a, p. 8).

12 The amount of $4 *$ ('world-leading') research increased by $70 \%$ in the REF so HEFCE allocated more to it. Originally the ratio was intended to be $3: 1$.

13 Similar calculations for Clinical Medicine (UoA1) show the unit funding multiplier to be $£ 17,197$; for Law it turns out to be $£ 11,026$; for Music it is $£ 13,194$. Again, these are the same for all universities in England.

14 The total mainstream QR research fund for England was $£ 1017$ million. The total London weighting on mainstream QR funding was $£ 33$ million. The total RDP supervision fund was $£ 240$ million. The total charity support fund was $£ 198$ million. The total business research fund was $£ 64$ million. The total funding for national research libraries was $£ 7$ million (HEFCE, 2015c, p. 16).

15 High-cost subjects are given higher weightings and the usual London weighting (of $12 \%$ and $8 \%$ ) applies.

16 The table is ordered by overall GPA.

17 The University of Oxford received the greatest share of QR funding at $£ 139$ million.

18 The occasional (very small) difference between these calculations and the numbers in Table 8 is due to rounding.

19 The 'Pearson product-moment correlation coefficient' or 'Pearson' for short is a measure of the linear correlation between two variables. It varies between +1 and -1 , where 1 is total positive correlation, 0 is no correlation and -1 is total negative correlation. It is the most widely used measure of the linear dependence between two variables. It is defined as the covariance of the two variables divided by the product of their standard deviations.

20 The 'Spearman rank correlation coefficient' or 'Spearman's rho' or just simply 'Spearman' is a non-parametric measure of statistical dependence between two variables. It assesses how well the relationship between two variables can be described using a monotonic function. If there are no repeated data values, a perfect 
Spearman correlation of +1 or -1 occurs when each of the variables is a perfect monotone function of the other. The Spearman correlation coefficient is defined as the Pearson correlation coefficient between the ranked variables. It can be used for both continuous and discrete variables, including ordinal variables.

21 Another possible cause ab initio for the Spearman and the Pearson being very different is the existence of outliers, but outliers would produce a high Pearson and a low Spearman because the Pearson is much more sensitive in that respect. As this is not the case here, we can discount this explanation.

22 A monotonically increasing function is a function between ordered sets that preserves the given order. The only condition is that it be non-decreasing everywhere.

${ }^{23}$ Unsurprisingly, Elsevier found that correlations were generally higher for UoAs whose assessment panels in the 2014 REF had actually used bibliometrics, but even here there were counter-indications: Physics used bibliometrics in the $2014 \mathrm{REF}$ but had a low correlation, whereas Business did not use bibliometrics and had a high correlation.

\section{References}

Bishop, D. (2015) Can metrics really replace reviewers in REF? Times Higher Education, 18-24 June (No. 2208), pp. 20-21.

Brown, M. (2007) On promoting rigour-a response, fournal of Education Policy, 22(3), 353-356.

Chambers, C. (2015) Can metrics really replace reviewers in REF? Times Higher Education, 18-24 June (No. 2208), pp. 20-21.

Else, H. (2015) Research funding formula tweaked after REF 2014 results, Times Higher Education, 20 February. Available online at: https://www.timeshighereducation.co.uk/news/researchfunding-formula-tweaked-after-ref-2014-results/2018685.article (accessed 1 November 2015).

Floud, R. (2015) Funding allocations: a whole lot of nothing, Times Higher Education, (Letters), 28 April (No. 2197), p. 32.

Frankel, M. \& Ransow, G. (2015) HEFCE gives more weight to $4 *$ research in new funding formula, Research Professional, 20 February 2015.

HEFCE (2009) Funding for universities and colleges in 2009-10. Available online at: https://www.jiscmail.ac.uk/cgi-bin/webadmin?A2 $=$ ind $0901 \& \mathrm{~L}=\mathrm{ADMIN}-\mathrm{HEFCE} \& \mathrm{~T}=0 \& \mathrm{~F}=\& \mathrm{~S}=\& \mathrm{P}=5163$ (accessed 16 February 2015).

HEFCE (2011) Assessment framework and guidance on submissions (updated to include addendum published in fanuary 2012), REF02.2011, para.79. Available online at: http://www.ref.ac.uk/media/ ref/content/pub/assessmentframeworkandguidanceonsubmissions/GOS\%20including\%20addendum.pdf (accessed 6 March 2015).

HEFCE (2015a) 2015-16 grant tables for HEIs. Available online at: http://www.hefce.ac.uk/funding/ annallocns/1516/1516hei/\#letterS (accessed 8 January 2016).

HEFCE (2015b) Funding for universities and colleges for 2013-14 to 2015-16: Board decisions. Available online at: http://www.hefce.ac.uk/pubs/year/2015/CL,032015/ (accessed 8 January 2016).

HEFCE (2015c) Recurrent grants for 2015-16, March 2015/05 (London, HEFCE).

Hong Kong University Grants Committee (UGC) (2014) Research Assessment Exercise (RAE) 2014. Available online at: http://www.ugc.edu.hk/eng/ugc/rae/rae2014.htm (accessed 8 January 2016).

Jump, P. (2014) Check your coordinates, Times Higher Education, 18-31 December (No. 2183), pp. 30-77.

Jump, P. (2015a) The race is not to the swift, Times Higher Education, 1-7 January (No. 2184), pp. 34-59.

Jump, P. (2015b) Winners and losers in HEFCE funding allocations, Times Higher Education, 26 March-1 April (No. 2196), pp. 6-9.

Jump, P. (2015c) Guess which part of 2014 REF came to $£ 55$ million, Times Higher Education, 2-8 April (No. 2197), p. 8.

Jump, P. (2015d) Can you win by fielding the whole team?, Times Higher Education, 7-13 May (No. 2202), pp. 20-21.

Jump, P. (2015e) Can metrics really replace reviewers in REF?, Times Higher Education, 18-24 June (No. 2208), pp. 20-21.

Kelly, A. (2012) Ranking the outcomes from the assessment of research in the UK, International Fournal of Management in Education, 6 (1-2), 74-87. 
Lucas, L. (2015) Education landscapes, research intensity, Research Intelligence, 126 (Spring), 1415.

RAE (2009) UOA 45 subject overview report. Available online at: http://www.rae.ac.uk/pubs/2009/ ov/ (accessed 12 February 2015).

Rothwell, N. (2008) RAE reaction: Go figure, Times Higher Education, 22 December.

Stronach, I. (2007) On promoting rigour in educational research: The example of the RAE, fournal of Education Policy, 22(3), 343-352.

THE (2015) Careers at risk after case studies 'game playing' REF study suggests, Times Higher Education, 22 January (No. 2186), p. 6.

Whiteley, P. (2015) Funding allocations: A whole lot of nothing, Times Higher Education, (Letters), 2-8 April (No. 2197), p. 32. 